\title{
The Three Dimensional Spiral of Sense: a New Paradigm Systemic Applied a Six Areas Disciplinares and Two Axis: Identity and Professionalization
}

\author{
Dr. Miriam Aparicio \\ Main Researcher CONICET. \\ National Council of Scientific Research (CONICET). \\ Universidad Nacional de Cuyo (National University of Cuyo). Mendoza. Argentina. \\ miriamapar@yahoo.com.
}

Tel +54 $2614251901 /$ +54 261154542284

\begin{abstract}
This article introduces a new systemic theory called "The Three Dimensional Spiral of Sense", applied to Identity and Professionalization. The epistemological mainstays of the theory are stressed here, a theory supported by more than 30 years of empirical research at CONICET (National Council of Scientific Research, Argentina), with individuals belonging to different populations, some of them covering periods of over 20 years (intra-generational studies), and others covering three generations in-line (inter-generational studies). This article presents the most specific theoretical frameworks, and it formulates the six disciplinary areas in which the new analysis of the social data was carried out: Education, Health, Science, Media, International Relations and Interculturality. The first area - Education - is dealt with through different levels (secondary level, tertiary level, University and PhD training. Here, we only make reference to the studies carried out, returning to some epistemological issues in this theory. The methodology used was quantitative (statistical analysis, a semi-structured survey) but mainly qualitative (hierarchical evocations, interviews). The approach was macro-micro-meso-macro, micro, not quite common yet. It consists of a kind of sui generis systemism which recovers relationships (links, back and forth) between individuals and contexts, without overlooking neither the former nor the latter, thus, avoiding any type of reductionism. Individuals, organizations and frameworks interplay and feedback themselves. The results, particularly the qualitative ones, show the rich interactions underlying the continuance or innovation processes, which favor or hinder the individuals' development and identity in times of abrupt change; at the same time, these results reveal the need for Professionalization in emerging countries.
\end{abstract}

Keywords: Systemic Sui Generis Paradigm, the Theory of the Three-Dimensional Spiral of Sense, Identity, Professionalization

\section{Introduction: Epistemological Support}

This theory or, if someone prefers, pre-theory is the result or synthesis of the principal research works done within the CONICET (National Council of Scientific Research) and since 1995 the Argentine Ministry of Education, Science and Technology.

The research was developed since 1995 along the lines of Social, Labor and Organizational Psychology, and its core issue was Achievement at University and at Work, and their mutual sustained interaction. My interest grew stronger, particularly in relation with the analysis of the impact (explanatory/quantitative level) and comprehension (qualitative level) of the psychosocial factors on achievement within the context of the international patterns related to Quality Assessment at University in its connection with the scientific and productive systems (for a case reference, see Aparicio, $2014 \mathrm{~b}$ ). The quality criterion leading us was pertinence, i.e., we observed the interactive analysis of the answers provided by the university system to the needs of the socio-productive and scientific world. This criterion was mostly overlooked at the international level. It should be mentioned here that this Assessment was started late in Argentina, in 1995, when the University Quality, combined with context, is first considered a priority. University polices emphasize the need to reach systemic analyses. However, Assessment comes down to figures, statistics, diagnoses, inputs and ouputs, but the human processes, which lie at the base of such figures, remain unknown in the Argentine system and, more globally, within the international framework, as it has been commonly pointed out literature until these days. Boudon, in 1973, invites us to work from a more integrating systematic perspective. It was a challenge to implement a systemic analysis of the factor with 
an impact on achievement at the macro level, and of the impact of the macro or micro organizational contexts on the individuals. My research is oriented in that direction, i.e., towards the search for a more holistic and comprehensive approach to analyze the "mechanisms" and/or factors that, when acting interactively, anticipate the achievement in three levels or dimensions: psycho-individual, meso-institutional/organizational and macro (Aparicio, $2015 \mathrm{c}$ and d). Such approach will let us surpass diagnosis and identify the interplay between the macro cosmos and the micro cosmos; a kind of resourceful play, such as the one between the individual, culture and society. In other words, our perspective aims at the comprehension of macro and meso organizational results and deals with the micro psychological and meso-institutional processes.

This new approach, which will reveal itself in the scientific production of 2005 and 2006 but which will be published in full in 2015 , comprises explanation and comprehension, quantitative and qualitative methodology, macro-micro-macro strategy analysis, processes and results, diachronic and synchronic and retrospective and prospective analyses, transdiscipline. It also includes factors of different kinds which interact and transform mutually into a self-ecosystem.

These theoretical-epistemological mainstays are presented here in this brief Introduction with the purpose of making results reading and interpretation easier.

I cannot retrace a long history or the core issues of the many research works (central or peripheral) developed. Nor can I make an inventory of the theories designed, or expand on the complementarity of certain micro-theories and/or factors which have been dealt with in literature in an isolated way, thus, overlooking the semi-dependence and semi-autonomy typical of the social and human phenomena.

On the contrary, I am definitely interested in emphasizing some key point on the method and other aspects related to underlying principles.

My open-circuit models include, at least, five factors: base, psychosocial, pedagogical/institutional, organizational and structural factors. They offer a double way, or "back and forth movement" between the individual and the (institutional or macro) context with positive and negative effects on the individuals and the institutions.

The research was carried out on populations covering two decades and also, the first studies were intergenerational. The first world study was made on three generations in line, 1977-1980. Large populations: As can be seen in some research presented here, we worked with very diverse populations: individuals who entered University since 1980/1985 (18 studycourses at UNCuyo (Cuyo National University) and 5 Engineering study-courses at UTN (National University of Technology) and, among them, some got their degree; others delayed their studies and another group dropped out studies. Others were developed with researchers, teacher researchers, doctors, university, tertiary level and secondary school teachers, organizations of the Judicial System (magistrates), university graduates working exclusively for the State, etc.

This broad time and space coverage of the research regarding "academic-professional careers" - 20 years in the lives of two universities - and broad also as regards university graduates' and students' predecessors - three generations: grandparents, parents and university students - let us analyze the meso/micro relation (organizations and individuals) within the "framework" of singular, family and group (cohorts) careers with remarkable differences at the macro social, economic and political level in Argentina.

In fact, working with large populations let us, on the one hand, determine the differences among the older university graduats' careers, who enter University in a different moment of our history, a time of prosperity in which they could realize their needs for achievement, their ambitions better than the previous recent graduates, who found themselves within a context of unprecedented institutional and economic crisis. The "back and forth" of the individual/structure system appears very clear (macro/micro level). On the other hand, working in the same organizational contexts, yet with data gathered from different historical, economic, social, educational moments, let us observe better the strong presence or weight of the macro level over the meso-organizational and micro levels as regards professional insertion and promotion (mobility) and many other variables which we cannot deal with now. The different environments, then, leave their imprint on the individual careers. 
The temporality (time) factor played a fundamental role regarding the possibility to observe the "back and forth movements" on the system with different consequences ${ }^{1}$. Moreover, it was a decisive factor in order to grasp the movements and selfsubstance loops between the three levels or dimensions of our theory, which would have been impossible had we not had small samples or worked only at one synchronic level, leaving aside the diachronic level. Besides, due to the combined methodologies and techniques applied, we could relive each of the actors' past, go over their history, with all that it involves, analyze their socio-professional situation at the time of our research, their projection for the future, their goals, ambitions, frustrations; their positions whether or not accompanied by recognition, their identity strategies in order to face difficulties...

The CONICET helped us reveal the differences and similarities according to factors, times and spaces and reach higher levels of generalization and higher levels of depth. From here, after years of research, emerged the mainstays which I now present in theses lines and summarize, even at the risk of simplification, my perspective, its stages, its transformations, and it theoretical-methodological issues, revealing a unit in dynamic and interactive "metamorphosis".

After analyzing this dynamic interplay in three levels (macro, meso and micro), which is called three-dimensional spiral of sense, and how to interpret this self-sustenance in different fields through the research works which have been by way of example-, finally, we will present a short Interpretation of results which we have referring to along the article and a Conclusion.

Let us stop for a moment in two core theoretical frameworks related to our research works.

\section{The Framework}

\subsection{About Identity and Professionalization}

The Professionalization matters (or better, lack of Professionalization) and its impact on personal and professional Identity, regarding their professional "future" and the possible performance of the individuals (Silva \& Aparicio, $2015 \mathrm{~b}$ ). Other issues are dealt with since: a) Career path, like identity, is in my opinion, a meeting place between a certain history, a biography, and the relational/structural level. That is, a context favoring or impairing the realization of different levels (Dubar, 1991; Aparicio, $2009 \mathrm{f}$ ). In fact, all identities are interwoven between the individual "the others" recognizing or not, and compel the individual to develop "surviving" identity strategies (Goffman, 1963), given the gap between what is desired and what is imposed/denied; due to the existence of "perverse" mechanisms; b) Identities are not shaped from nothingness but from institutions (family, school, business, etc.). The interplay of individuals, institutional and macro contexts is shown clearly.

We have worked on two core issues: identity related to professionalization in the field of formation, and professional insertion.

Professionalization has been source of long debate since the 80s (Lang, 1999). On the one hand, the effects of "overcrowding" in higher education (Bourdoncle \& Demailly, 1998) has emphasized the need to consolidate certain competences and sets of knowledge essential for professional practice and its corollary, social recognition of professional groups (Bourdoncle, 1993). The quick changes within the professional world demand innovative transformations in training institutions and consolidation of new competences valued by the market. On the other hand, as regards this research, the conditions of professional practice in the working world have changed, and professional insertion as well as duration and promotion represent a complex problem.

In the specific field of training, the new professionals encounter various difficulties, in addition to lack of recognition. Some authors even speak of de-professionalization of those graduates on this field (a process of "proletarianization" (Ozga \& Lawn, 1981); the "semi-professional" status in a broad sense (Etzioni, 1969), the devaluation of the graduate's image in the field of education (training) along with an ever growing weakening (burnout) (Tardiff \& Lessard 1999); Maroy 2006; Aparicio,

1 See Aparicio, 2005 a and 2009 c. In this research, "Temporality" and its impact on professional achievement and associated careers take up a full chapter. 
2006 a, 2006 b, 2007 a, 2007 b, 2009 a, 2009 b, 2009 c, 2013 a). In general, it can be said that there is a certain tension between the area of work and the area of training, as well as between the expectations at the moment of vocational choice and the actual experience in the professional environment; also, between the "ideal" situation expected by the PhD students and the real one of the $\mathrm{PhD}$ graduates; between the representation of the doctors and their world experience. Is there an identity crisis as regards the deep changes in the labor market and as regards expectations? (Goffman, 1963). Is there certain overprescription in the institutions to respond to the changes in the labor market along with underprescription in the means used to such response, as it is usually said? Within this framework, the links between the personal training experience and the professional life become a source of concern in the field of training and, especially, in the studies related to humanities and social sciences.

Besides, this issue involving institutional and even disciplinary identities, as well as the identity reconstruction processes, is accompanied, as it has just been said, by actual insertion conditions, duration and professional mobility; all of them will have an impact on professional careers (Dubar 1991, 2000 a, b and c).

Identity is, then, the result of a history and a certain time marked by specific contextual characteristics (Aparicio, 2013 a). Argentina there appears the existence of a favorable context to the identity crisis. Uncertainty prevails - within a context in which Professionalization has not developed adequately.

Two final words about this theme: Identity and Professionalization.

As regards Identity, we cannot expand any more at this point. We refer to our own work and other international literature (Aparicio, $2012 \mathrm{c}$ ). There the reader will be able to find different form of identity (ethnic, professional, cultural, sexual, ...); the different approaches - sometimes opposites - unity, decentration, essentialism vs. constructivism, difference vs. resistance); identity in terms of transaction. The processes related to Identity are also shown (individualization, identification, attribution and introjection, conservation, narcissism, realization); the most prominent perspectives (behaviorism, genetic, clinical, social and psychosocial views...); perspectives associated to cultural anthropology, to symbolic interactionism, to phenomenology, to systemism). Identity appears in the interweaving of history, biography and relations, it always involves an "alter" - other - who may or may not recognize, may or may not accept.

As regards Professionalization, as is widely known, it affects people, job positions, professions, groups, and from it comes the so called Professionalism. There usually exist different approaches to the issue. Once again, we can see here our levels, at least, the micro and meso levels.

Professionalization has 2 purposes: acquiring collective capacities, previously dealt with by Bourdoncle \& Demailly (1998), and internalizing cultural and professional rules (autonomy, polyvalence, team work). Thus, those who are responsible within the labor market try the individuals to identify themselves with the aims of the company and get involved with the identity model the company follows. However, conflict often arises between the personal and the collective projects and the individual hast to resort to identity strategies.

In all cases, Professionalization tends to reduce the gap; this gap is smaller in some cases than others.

Finally, finding the link between Burnout and inadequate Professionalization is not difficult, since it refers to a syndrome characterized by a fall in expectations.

\subsection{Theories of Achievement}

There are various causes related to achievement / failure, and in addition to this problem there is the unambiguity of the term "failure": the definitions refer to different aspects, such as poor performance, course repetition, drop-out, poor education quality, school maladjustment, etc. Failure is also linked to physiological, psychobiological and family background factors.

Achievement Related Approaches: Studies by Cabrera and Nora (1994), offer five broad categories to classify the approaches related to dropout and retention, considering whether the emphasis assigned to the core explanatory variables falls on personal, family, or institutional factors. We can identify five approaches: psychological, sociological, economic, organizational and interactionist, which are supported by empirical research. 
Different models show the impulse of adaptation to university life and acceptance of the fashion or "identity" each institution presents; the role of engagement and positive interactions among students and with teachers, as well as the role of perspective, which, as stated by Tinto $(1975,1987,1993)$, exhibits an individual side and an academic one. Nevertheless, Tinto is one of the principal writers about this subject and particularly about the causes of drop-out. This relationship between socio-academic inclusion and retention has been also observed in studies with representative samples at the national level in the US (Astin, 1991; Horn, 1998; Leppel, 2002; Thompson, 1990; Tinto, 1998) and in studies on a single institution (Eaton \& Bean, 1995; Thomas, 2000).

Bean, 1980; Bean \& Metzner, 1985 adds the persistence factor to Tinto's model on behavioral intentions within the business labor framework. He states that institutional (external) factors, such as the programs offered by a university or the interrelationship between students and teachers, may have an impact on the student's decision to endeavor to persevere. Satisfaction with the institutional offer could work in like manner. Therefore, we can see that focus is on organizational/institutional, environmental, and non-cognitive personal factors (ambitions, motivations, interests, etc.).

Pascarella (2001; Pascarella \& Terenzini, 1991, 2005) suggests, in turn, a model that combines institutional and environmental features, distinguishing five groups: 1) personal features (aptitudes, performance, personality, ambitions, and ethnicity); 2) structural and organizational factors (admission systems, selectivity); 3) environment; 4) interactions within university life; and 5) the quality of students' effort.

A more recent approach, the psychosocial approach, claims that it is necessary to test the relationship among motivation, social and institutional constructs. Studies carried out in the US also show that the best predictors for graduation are academic training and students motivation (Adelman, 2004; Pascarella \& Terenzini, 2005) 1.

Compared with the foregoing methods, ours integrate a variety of these factors grouped in the last two approaches: psychological and organizational (see especially Aparicio 2005 a, 2006 a and b; 2008 a and b). Some variables used in the afore mentioned models are incorporated and the impact of these variables on the subjective and objective achievement is analyzed based on quantitative methodologies and predictive models (Aparicio, $2005 \mathrm{a}$ ); on the other hand, in the light of qualitative methodologies, we intend to account for the origin and sense of this problem in the students' personalprofessional experiences.

In this study, we deal, especially and always from a qualitative point of view, with the psychosocial aspects of the problem (processes leading to failure), and the institutional aspects, which have been observed in some typical practices identifying each course of study and, in a more global manner, the university. Both aspects are combined based on an integrating perspective without disregarding educational institution, nor the individuals and their sociocultural background (close and distant), nor the structural present context. However, the latter is part of our analysis only as a secondary aspect, whether from the viewpoint of degree devaluation in the labor world, or from the discontent students express (i.e., from their opinions as regards these poor institutional practices in relation to the higher demands of the labor market). All this has an impact on the perseverance and success in studies and employability. Individuals, institutions and macro-social contexts interweave in this analysis.

The meso-institutional and micro-personal levels within a structural background of crisis (underemployment, high unemployment rated, even for university graduates, etc.) are self-sustainable in this integrating and holistic perspective (Aparicio 2008 a, 2009 a and b, 2009 c, 2012 a, 2012 b, 2015 c and d). Here lies the uniqueness of our quantitative/qualitative sui generis model.

General Hypothesis: within achievement at university level there exist different factors: individual (objective and subjective), pedagogical, institutional and structural (labor market). Their interaction operates selection in higher education.

Specific Psychosocial Hypotheses: a) Psychosocial factors (combine aspects of the individuals and their context) favor academic and/or work failure. b) Ambitions, expectations and n-Ach (need achievement) have a specific impact on the selection which operates before and during entering university as well as during the course of studies. $c$ ) These factors together with others (pessimism of perspectives, dissatisfaction, anomy, etc.) create achievement patterns which are

1 For more details, see Aparicio (2014 a). 
different according to the courses of study, whether favoring achievement or not. d) All this benefits different institutional identities linked to biographical-contextual identities of the individuals.

\section{The Epistemological Mainstays Applied to Six Disciplinary Areas}

We have developed this non-linear, non-determinist, integrating and holistic (systemic sui generis) theory after working for over 30 years, researching on complementary areas. At this point, we cannot go into details in each of the research works (Aparicio $2015 \mathrm{c}$ and d). We will simply point out the core disciplinary areas with a brief reference to the self-sustained interplay of the variables; such interplay will eventually let us grasp the "sense" of human and/or social phenomena we have dealt with. To conclude, we will point out some epistemological issues supporting this theory.

\subsection{Education, with special application to Professionalization and Identity}

This issue is present in several research works (university graduate students, drop-outs, delayed students -1980-2004-; in a second moment, the research is carried out up to present days. We will also worked with students "retained" within the system and $\mathrm{PhDs}^{1}$ ). Teachers and although sometimes Authorities and Officers of the Political/Educational and Labor area are also included.

The studies were carried out at different universities: Universidad Nacional de Cuyo (Cuyo National University) - UNCuyo -, Universidad Tecnológica Nacional (National University of Technology) - UTN -, and Universidad Austral (Austral University), all of them in Argentina (Aparicio $2015 \mathrm{c}$ and d). Finally, we added individuals of Non-University Tertiary Level (i.e., studies with individuals studying at Teacher Training Institutes, INFD). They have quite distinct profiles. Our research showed the differences and similarities related to the interaction of individuals, macrosocial/structural contexts and institutions. This reveals the presence of different institutional and personal/professional identities largely related to excellence at University or in their Study courses and to the level of Professionalization achieved.

\subsection{Health}

It is another field we have dealt with in which the interplay between the macro, meso institutional and micro levels emerge clearly. We have carried out several research works on the three mentioned levels:Burnout in different populations (some are cooperative studies) and Factors operating "para-choc" (measured quantitatively): Engagement, Well-being, Optimism, Pessimism, Resilience, Coping or strategies to cope with adversity (helping improvement and/or controlling it), attributive factors such as Alignment, Internality, application or motivational factors (2005 a, $2009 \mathrm{a}$ and b, $2014 \mathrm{~d}, 2015 \mathrm{c}$ and d).

Among the qualitative dimensions, we can mention: Personal and Professional Expectations, N-ach/Ambitions, Sense of Effort and Engagement, Resilience (importance of building firm and solid bonds). Other aspects related to the importance of Professionalization appear here (teachers' support mechanisms, level of social and for-life competences formation

1 This research includes doctors in education at National University of Cuyo, 2005-2009), and doctors under training in Adult Education at Cnam (National Conservatory of Arts and Crafts, France). Two research laboratories took part in this work: the Laboratorio de Investigaciones en Educación (Education Research Laboratory, Conicet/UNCuyo, Argentina and the CRF, Centre de Formation sur la Recherche, Cnam). It is expected to find different profiles according to the work/professional contexts in which they are situated together with the differences of the respective contexts in our country and with the contributions from the micro level: the problems, values and priorities appearing in the social representations shared by each of these groups. As we can see, this lets us see different institutional, personal and professional identities as well as different aspects along their professional career.

The results show no obvious differences are noticed between the French and Argentine groups. Doctoral training is valued by both groups; that is, although the general idea is that $\mathrm{PhD}$ degrees are devaluated, subjectively, doctors are quite satisfied. Along this line, they expect improvements in their future work life, thus a positive view prevails. On the contrary, other graduates on education without a PhD degree do not show the same prospect. Briefly: doctoral education (Argentine) is still considered an "add-on". The strongest claim against labor market lies on the lack of recognition, especially among the French doctors. Comparatively, the Argentine group has higher expectations as regards the degree. The "plafond" effect linked to the context appears in our research. The self-sustaining movement the links (back and forth movements) - appear as the result of this interplay (Aparicio, 2015 a, c and d). 
beyond procedural and disciplinary competences, satisfaction - although not always related to economic aspects or hierarchical position, among other aspects) (Aparicio 2005 a; 2007 a and b; Aparicio \& Cros, 2015 a).

Once more, each study reveals similarities and differences by educational organizations or institutions which feedback on each other thorough time (we should remember that studies cover large periods of time, which shows theses self-sustaining socio-cultural, psychosocial, organizational and structural variables), both at institutions/faculties/study courses offering unique profiles with predominantly positive or negative aspects, and in individuals. Such self-sustenance also shows institutional selection processes and self-selection.

\subsection{Science}

On this field, we carried out a research work, a replication of the important research done by the UNESCO $(19711,1979$, Knorr, K., R., Mittermeir, G., Aichholzer, R., Waller, G, among others).

We work with Team Chiefs and Team Members. The statistical analysis clearly shows the existance of "Invisible Schools"; schools referring to institutional and disciplinary identities (Crane, 1972; Aparicio, 2014 b, 2015 d)2. Our work combines the three levels of the theory: macro structural (political-economic), méso organizational (research teams), and micro individual: researchers (Chiefs and Members). Interaction and self-sustenance appear clearly at the three levels within Dr. Aparicio's theory called "Three-Dimensional Spiral of Sense".

The findings reveal the relation between Disciplinary Identity/identities (hard sciences vs. soft sciences, with their rules, values, etc.) and Institutional Identities in an unfavorable macro/structural context, all of which leads to a low level of Professional Satisfaction with consequences at the level of anomy, pessimism, etc. The three levels are again in their selfsustained interaction, in a relation of partial dependence and partial autonomy.

\subsection{Media and Institutional Cultures}

This study tests hypotheses included in the psycho-socio-communicational paradigm, which emphasizes the long term cognitive effects of the media and the role of the psychosocial subject as recipient: the hypothesis of "agenda-setting" (Cobb \& Elder, 1971; Mc Combs \& Shaw, 1972; Gerbner \& Gross, 1976; Ettema \& Cline, 1977; lyengar, 1979; Bregman \& Missika, 1989; Aparicio, 1995 a).

Institutional homogenization - particularly between different faculties and/or study courses - is surprising and makes us rethink the role of the university in educating for the critical reading and filtering of the material the media provide as (Pasquier, 1994; Aparicio, 2013 b).

As far as we are concerned, we wished to analyze the appearance of the individuals / contexts relation in their sustained interaction. This was possible thanks to the extensive time of our research in a changing structural framework and carried put in several study courses (micro-organizations) of the UNCuyo (Aparicio, 2002; 1980-2004 and 2005-2014).

Objectives: a) To elucidate such effects in audiences with different levels of education, b) To detect levels of manipulation and homogenization of the "mental maps" linked with the centralization of the "fourth power", c) To analyze if institutional affiliation (different faculties and/or study courses) has an impact on the "filter of the news" from the point of view of the prevailing ideology, beliefs, defining purposes, priorities. In other words, we wished to determine if such institutional affiliation influences on the cosmovision of the individuals in them (here, the students), contributing to the design of such mental maps.

Hypothesis: The central hypotheses are offered, taking into account that forty nine were considered: a) there would be a marked correlation between the order of importance assigned to the information by the media and that adopted by youths (high incidence of "mental construing"), b) receptivity of the addressees would vary according to cognitive competence; c) 
the institutional characteristics could impact on a different interpretation of the social reality, producing certain homogenization in the "mental map" of the individuals in them.

Results show different interpretations and levels of "filtering" in accordance with the pertaining institution. As far as we are concerned, there exists a clear institutional influence in the cosmovision young people as regards the news selection they make of the offers of the media. Individuals and contexts once more in their interplay.

The micro/meso interplay is evident; i.e., personal identities getting feedback from institutional identities (Aparicio, $1995 \mathrm{~b}$, 2005 b).

\subsection{International Policies, Cooperation and Relations ${ }^{1}$}

The purpose was analyzing a study about the impact of Food Allowance - a program implemented by international organizations - within the framework of the fight against hunger in an unpromising context which puts the Goals of the Millennium at risk. It is especially interesting to see how the quantitative variables and the qualitative dimensions appearing at the macro level (political and economic in particular) also occur at the meso level (regional) and, on the basis, at the micro level. The mainstays of the theory appear clearly again, although the areas and disciplines change since work is no longer on-site.

This disciplinary area interweaves with many others, especially, with axis-variables in Social, Community and Health Psychology and Psychosociology (field of research).

Professionalization does not play a direct role, although it does appear when dealing with improving the Management on the Matter, which has an impact on these International Programs and their quality (Cf. Santander Aparicio, 2012).

\subsection{Interculturality}

We work with Native Peoples (Natives) of Argentina (Huarpes, Kollas, Wichis, Aymaras and Mapuches) and Chili (Mapuches). Also with ethnic minorities. The study refers to a more recent issue in our context, although its roots come from long ago, in a history plagued with prejudices, stereotypes, discrimination against those who were different, against the others. All these aspects have often been concealed under words of "acceptance of diversity". Comparative studies from Argentina and other countries are presented here, revealing personal and professional identities always interwoven between the individual and his/her immediate and macro context in a sustained interplay. . In fact, the institutions are not prepared to welcome and nurture "the other one", "the different one" although international laws spread and this problem is increasingly evident in the public an school policies debate. (See Wieworska, 1996, 2008; Aparicio, 2014 g, h, i, j; $2015 \mathrm{c}$ and d). It can also be clearly observed quasi absence of Professionalization regarding Interculturality and diversity. Finally, it can be observed that Professionalization and Identity have strong implications on practices and, globally, on personal and institutional achievement or failure levels, and deep down, on the macro system.

\section{Interpretation of Results}

It would be impossible to deal at this point with the results according to factors, in themselves and their dynamic/systemic interaction or "back and forth" movements between individual and contexts within the different research works. As for the rest, some of them have been presented in or derived to the work which deals with them in full 2 .

I will simple remark some theoretical-methodological contributions and limits and the theoretical/model nodes which get us closer to a renewed theory.

In principle, the analysis revealed differences and similarities in relation with the discoveries in Argentina and other countries (particularly, French speaking countries).

1 The author was advisor in theoretical-methodological matters. See Santander Aparicio, 2012.

2 For a synthesis, see Aparicio, HDR, 2007 a and b. 
This is quite important from the point of view of the construction of our theory. In fact, we could see the change of sense shown by some variables in relation with the findings of other European studies. This could reveal a key aspect in our framework: the importance of the interplay between the individuals and their context (here, the institutions/organizations in the labor market, the State, all this on a macro framework, of different priority origins and problems); it could also reveal the importance of a "contextualized" analysis and of a methodological approach aiming at recovering the sense of human behaviors or actions within the "back and forth" movement between the individuals and their contexts; finally, it could reveal the importance de specific reappropiation of the disciplines involved based on a comprehensive approach. The observed differences, in fact, let us outline new approaches and invited us to review theories and methods.

The similarities found in this work let us infer the existence of a certain disciplinary, institutional, organizational and also and basically cultural homogenization in vivo; a certain "standardization" already appearing in the first research works (descriptive level), which will eventually melt the differences (both at the level of the individuals and the organizational level), with the aim of protecting institutional identity.

In fact, our results gradually showed that there are homogeneous profiles inside the faculties of one University, according to academic units/faculties and academic "areas" ("hard sciences" versus "soft sciences"). Such homogeneity within each institution could be expected to some extent; however, it surprised us due to its extended presence and "power".

From the theoretical-methodological point of view, our framework - multi-referential - has also let us, overcome the barriers that trap thinking with the burden of certain "-isms" (sociologism, psychologism,...), and led us to find points of contact. The different approaches interwoven in our research (psychosocial, psycho-sociological, sociological, in the field of education, human resources administration, management, occupational medicine, ...), has finally let us relativize the theses supported within the framework of other theories. They showed that our objective is complex yet not determined.

Finally, it provided us with a comprehensive interpretation of what was our sub-issue in this presentation of the Theory of the Three-dimensional Spiral of Sense: the problem of Identity and Professionalization. We carried out the analysis taking the intergenerational, social and professional careers as one of its guiding themes.

Three-Dimensional Spiral of Sense, a name which makes reference to the non-linear relations within the social and human phenomena, which may be better understood in diverse disciplinary areas (interdiscipline and transdiscispline), until a deep sense is reached in many cases, if we consider three dimensions in a self-sustained interplay: society, culture and the individual, or, in other words, the macro, meso and micro levels.

Let us try to answer the following question: What epistemology we could use to analyze the careers?

A career basically comprises a personal history and the influences of the context. It also confers a certain identity and "speaks" of the levels of professionalization. As a complex phenomenon in which multiple variables participate, it requires a sui generis systemic interpretation, away from the classical and administrative systemism, in which the three aforementioned levels appear in a dynamic way with unpredictable (positive and negative) effects. Thence, I decided to represent (a career) as an open spiral upwards and downwards, with multiple factors and/or dimensions interwoven in a semi-dependence and semi-autonomy relation; a spiral in which there is room for freedom and chance (and the uncertainty this fact involves), in which there is room for a kind of curiously "limited" freedom" yet not determined by context; a spiral comprising society, personality and culture and it is deeply rooted in socialization, in a broad sense (family, organizations, country or cultural ethos).

This interweaving will reveal the presence of the macro in the meso and the micro, and the micro in the meso and the macro; the imprint of the institutional culture on the individuals and, at the same time, the individuals will be the bearers of such culture. Therefore, culture will appear as producer and produced, being at the heart of the interplay.

\section{References}

Adelman, C., 2004. Principal Indicators of Student Academic Histories in Post-Secondary Education, 1972-2000. Washington, DC: U.S. Department of Education, Institute of Education Sciences, http://www.ed.gov/rschstat/research/pubs/prinindicat/index.html.

Aparicio, M., 1995 a. Educación Superior y Empleo. Propuesta de un modelo sistémico, Ph.D. Thesis, Universidad Católica Argentina Santa María de los Buenos Aires, Argentina. 
Aparicio, M., 1995 b. Agenda-Setting. Un análisis desde sus supuestos e implicancias educacionales, Master Thesis in Education Social Communication and Human Relations, UCA, 2 Vol.

Aparicio, M., 2005 a. Les facteurs psychosociaux en relation avec la réussite universitaire et professionnelle, PhD. Thesis. Université Paris V, Sorbonne, France.

Aparicio, M., 2005 b. Cultura institucional y "homogeneización mental". Un análisis de impacto en universitarios. Interdisciplinaria, 22(2), 115-123.

Aparicio, M., 2006 a. Trayectorias universitarias. Un análisis a la luz de metodologías cuantitativas, ZETA, Mendoza.

Aparicio, M., 2006 b. Trayectorias universitarias: Un análisis a la luz de metodologías cualitativas, ZETA, Mendoza.

Aparicio, M., 2007 a. Les facteurs psychosociaux à la base de la réussite universitaire et professionnelle: aspects psychologiques et organisationnels, HDR (Psychologie), Lille, Université Lille 3.

Aparicio, M., 2007 b. Mobilité et réussite universitaires et professionnelles. Du niveau macro au niveau micro. HDR (Education), Université Paris X, Nanterre.

Aparicio, M., 2008 a. Causas de la Deserción en Universidades Nacionales, Ed. San Juan National University, San Juan.

Aparicio, M. et al., $2008 \mathrm{~b}$. Social représentations of the teacher profession and the social construction on professional identities at the beginning of the teaching carrier. A french-argentinian study: IFM de Créteil (Francia) e Institutos de Formación Docente de Mendoza (Argentina). Ministerio de Educación, Cooperación bilateral franco-argentina.

Aparicio, M., 2009 a. La demora en los estudios universitarios. Causas desde una perspectiva cuantitativa, EDIUNC, Mendoza.

Aparicio, M., 2009 b. La demora en los estudios universitarios. Causas desde una perspectiva cualitativa, EDIUNC, Mendoza.

Aparicio, M., 2009 c. Les facteurs psychosociaux et la réussite universitaire et professionnelle, ANRT, Lille, Université de Lille 3.

Aparicio, M., 2009 f. Opening Conference, Congrès de l'Ecole de Gestion: Nouvelles carrières. Nouvelles compétences. Les trajectoires universitaires et professionnelles: entre formation et travail, Faculté des Sciences de la gestion, Université de Rouen, 13-14 May.

Aparicio, M., 2010. La evaluación de la Calidad del Sistema Universitario y de Empleo en su articulación ¿Hacia un paradigma sistémico transdisciplinario? Revista Iberoamericana de Educación (RIE), OEI, January 2010, 1-32.

Aparicio, M., 2012 a. La deserción universitaria y su relación con factores psicosociales. Revista Dialogo, 20, 28-39.

Aparicio, M., 2012 b. Trajectoires universitaires/professionnelles et identité. In J. Clénet, Ph. Maubant, D. Poisson (Eds.), Formations et professionnalisations: à l'épreuve de la complexité, L'Harmattan, Paris, 195-229.

Aparicio, M., 2012 c. Crise d'identité et devenir professionnel des étudiants qui sont engagés dans un doctorat en éducation/formation. Une approche comparative franco-argentine. Biennale internationale de l'éducation, la formation et des pratiques professionnelles, Cnam, París. July 4-6.

Aparicio, M., 2013 a. Formación de formadores y Profesionalización en Argentina: Un análisis de la situación macrosocial, meso-institucional y su impacto sobre las trayectorias e identidad de los formadores. In A. Arbós, P. Puig Calvó (Eds.). Universidad y Sociedad: Formación, Profesionalización y Validación de la Experiencia, Furtwangen Editores, Barcelona, 195-209. This study is the translation of the presentation at the Opening of the IRPÉ, Université de Sherbrooke, Canada, directed by Ph. Maubant, entitled "La formation des enseignants. Tableau de la situation en Argentine dans le cadre de la coopération bilatérale".

Aparicio, M., 2013 b. The Media and the Configuration of "Mental Maps": Their Relation to Institutional Homogenization among University Students and Disciplina Identities. Mediterranean Journal of Social Sciences, 11, 4, October, 235-238 (ISBN 2039-9340-print).

Aparicio, M. 2014 a. University Drop-Outs. A Systemic Play of Subjects, Institutions and Macro Contexts, Journal of Educational and Social Research, 4, 2, Special Issue - April. ISSN 2240-0524.

Aparicio, M., 2014 b. Satisfaction, Professional Mobility and Leadership in Academic-Scientific Organizations, Journal of Health Science, 2, 3, 135-145. 
Aparicio, M., 2014 c. Postgraduate Level and its Impact on Academic Studies and Professional Careers, Social and Job Mobility and Identity. A Study about PhD Graduates and PhD Students at UNCuyo, in the Light of a sui generis Paradigm, Journal of Educational and Social Research, 4, 2, Special Issue - April.

Aparicio, M., 2014 g. Interculturalidad en la Universidad, Mendoza (Argentina), Zeta, 7-12.

Aparicio, M., 2014 h. Prefacio. In M. Aparicio (Ed.), Interculturalidad en la Universidad, Mendoza (Argentina), Zeta, 7-12.

Aparicio, M., 2014 i. Acerca de la cultura y las concepciones epistemológicas dominantes. In M. Aparicio (Ed.). Interculturalidad en la Universidad, Mendoza (Argentina), Zeta, 13-22.

Aparicio, M., 2014 j. Del Multiculturalismo a la Multiculturalidad e Interculturalidad: Un Camino por Construir. In M. Aparicio (Ed.), Interculturalidad en la Universidad, Mendoza (Argentina), Zeta, 23-43.

Aparicio, M., Cros, F., 2015 a. Trajectoires et identités. Un avenir incertain pour les docteurs? L'Harmattan, Paris, Collection Education et Sociétés.

Aparicio, M. (2015 b). Identity, Weakening and Professionalization: A Study of Graduate and Postgraduate Students (1987-2002) in the Light of the Three-Dimensional Spiral of Sense Theory. In International Handbook of Professional dentities, A. M.Costa e Silva \& M. Aparicio (Ed.). USA: Scientific \& Academic Publishing, 121-156. ISBN 978-1-93868135-6.

Aparicio, M. (2015 c). Towards a sui generis systemic theory: The Three-Dimensional Spiral of Sense. A Study in Argentina Applied to Identity and Professionalization (Article 1). Asian Academic Research Journal of Social Sciences \& Humanities (AARJSH) [ISSN 2278 - 859X].

Aparicio, M. (2015 d). The Theory of the Three-Dimensional Spiral of Sense: An Application with special Reference to Identity and Professionalization in other Disciplinary Areas (Article 2) Asian Academic Research Journal of Social Sciences \& Humanities (AARJSH) [ISSN 2278 - 859X].

Astin, A., 1985. Achieving Educational Excellence: A Critical Assessment of Priorities and Practices in Higher Education, Jossey-Bass, San Francisco.

Astin, A., 1991. Assessment for Excellence: The Philosophy and Practice of Assessment and Evaluation in Higher Education, Macmillan, New York.

Bean, J., 1980. Dropouts and turnover: The Synthesis and Test of a Causal Model of Student Attrition, Research in Higher Education, 12, 155-187.

Bean, J., Metzner, B., 1985. A Conceptual Model of Nontraditional Undergraduate Student Attrition, Review of Educational Research, 55, 485-540.

Becker, G., 1964. Human Capital, National Bureau of Economic Research, New York.

Boudon, R., 1973. L'inégalité des chances, PUF, Paris.

Bourdoncle, R., 1993. La professionnalisation des enseignants: les limites d'un mythe. Revue française de pédagogie, 105, 83-119.

Bregman, D., Missika, R.,1989. La fonction d'agenda: une problématique en devenir, Hermes, 4, 17-24.

Cabrera, A., Nora, A., 1994. College Students'Perceptions of Prejudice and Discrimination and their feelings of Alienation: A Construct Validation Approach, Review of Education/Pedagogy/Cultural Studies, 16, 387-409.

Cobb R., Elder, C., 1971. The Politics of Agenda-Building: An Alternative Perspective for Modern Democratic Theory. The Journal of Politics, 33, 897-915.

Crane, D., 1972. Invisible Colleges, University Chicago Press, Chicago.

Dubar, C., 1991. Formation continue et dynamique des identités professionnelles, Formation et Emploi, 34, 87-100.

Dubar, C., 2000 a. La socialisation. Paris: Armand Colin. Dubar, C., 2000 b. La formation professionnelle continue, La Découverte, Paris.

Dubar, C., 2000 c. La crise des identités, PUF, Paris.

Ettema, J., Cline, F., 1977. Deficits, Differences and Ceilings: Contingent Conditions for Understanding the Knowledge Gap. Communication Research, 4, 39-47. 
Etzioni, A., 1969. The Semi-Professions and Their Organizations, The Free Press, New York.

Eaton, S., Bean, J., 1995. An Approach/Avoidance Behavioral Model of College Student Retention, Research in Higher Education, 36, 617-645.

Goffman, E., 1963. Stigmates. Les usages sociaux des handicaps, Minuit, Paris.

Horn, L., 1998. Stopouts or Stayouts? Undergraduates who Leave College in their First Year (Statistical Analysis Report $N^{\circ}$ NCES 1999-087), U.S. Department of Education, Office of Educational Research and Improvement, National Center for Education Statistics, Washington, DC.

Iyengar, S., 1979. Television News and Issue Salience: A Reexamination of the Agenda-Setting Hypothesis. American Politics Quaterly, 7(4), 395-416.

Knorr, K., R., Mittermeir, G., Aichholzer, R., Waller, G., 1979. Leadership and Group Perfomance. In F.M. Andrews, (Ed.), Cambridge University Press, Cambridge, pp. 55-120.

Kuh, G. D., Hu, S., 2001. The Effects of Student-Faculty Interaction in the 1990s, Review of Higher Education, 24, 309332.

Lang, V., 1999. La professionnalisation des enseignants, PUF, Paris.

Leppel, K., 2002. Similarities and Differences in the College Persistent of Men and Women, Review of Higher Education, $25,433-450$.

Lévy-Garboua, L., 1976. Les demandes de l'étudiant ou les contradictions de l'université de masse, $R$. Française de Sociol., 17(1), 53-80.

Lévy-Garboua, L., 1977. Les demandes de l'étudiant ou les contradictions de l'Université de masse : réponse aux commentaires, R. Française de Sociol., 19(1), 147-156.

Maroy, C., 2006. Les évolutions du travail enseignant en France et en Europe: facteurs de changement, incidences et résistances dans l'enseignement secondaire, Revue Française de Pédagogie, 155, 111-142.

Function of Mass Media. Public Opinion Quaterly, 36, 176-187.

Ozga, J.; Lawn, M., 1981. Teachers Professionalism and Class: A Study on Organised Teachers, Falmer Press, London.

Pascarella, E., 2001. Identifying Excellence in Undergraduate Education: Are we even Close? Change, 33(3), 19-23.

Pascarella, E., Terenzini, P., 1991. How College Affects Students: Findings and Insights from Twenty Years of Research, Jossey-Bass, San Francisco.

Pascarella, E., Terenzini, P., 2005. How College Affects Students: A Third Decade of Research (Vol. 2), Jossey-Bass, San Francisco.

Pasquier, D., 1994. Vingt ans de recherches sur la télévision. Sociologie du Travail, XXXVI, 1, 63-85.

Santander Aparicio, M., 2012. El Rol de la Ayuda Alimentaria en el Contexto de la Lucha contra el Hambre Mundial: Un Análisis de sus Efectos Positivos y Negativos. Master Thesis. Relaciones Internacionales. FLACSO. San Andrés University and Barcelona University.

Tardif, M., Lessard, C., 1999. Le travail enseignant au quotidien. Expérience, interactions humaines et dilemmes professionnels, De Boeck Université, Bruxelles-Paris.

Thomas, S., 2000. Ties that Bind: A Social Network Approach to Understanding Student Integration and Persistence, Journal of Higher Education, 71, 591-615.

Thompson, C., 1990. Predicting Involvement and Educational Attainment: A Study of Black Students in Black and White Colleges. Paper presented at the Meeting of the American Educational Research Association, Boston.

Tinto, V., 1975. Dropout from Higher Education: A Theoretical Synthesis of Recent Research, Review of Educational Research, 45, 89-125.

Tinto, V., 1987. Leaving College: Rethinking the Causes and Cures of Student Attrition, University of Chicago Press, Chicago. 
Tinto, V., 1993. Leaving College: Rethinking the Causes and Cures of Student Attrition (2nd ed.), University of Chicago Press, Chicago.

Tinto, V., 1998. Colleges as Communities: Taking Research on Student Persistent Seriously, Review of Higher Education, 21, 167-177.

Silva, A. M., Aparicio, M. (Eds.). 2015 b. International Handbook about Professional Identities, Academic and Scientific Publishing, USA.

UNESCO, 1971, International Comparative Study in Organizations and Perfomance of Research Units, UNESCO, Paris.

Wiewiorska, M., 1996, Une société fragmentée ? Le multiculturalisme en débat. La Découverte, Paris.

Wiewiorska, M., 2008. La diversité. Laffont, Paris. 